\title{
PENGARUH PENGEMBANGAN KARIR, FASILITAS KERJA, KOMITMEN PROFESI DAN PENGAWASAN KERJA TERHADAP KINERJAPEGAWAI PADA KANTOR PELAYANAN PAJAK PRATAMA TEBING TINGGI
}

\author{
Rahmadsyah \\ Universitas Islam Sumatera Utara \\ mhd.jonihidayat@gmail.com
}

\begin{abstract}
The problem in this research is how the influence of career development, work facilities, professional commitment and supervision of work partially or simultaneously on the performance of employees in the Tebing Tinggi Pratama Tax Office The research objective: To determine the effect of career development, work facilities, professional commitment and work supervision partially and simultaneously on the performance of employees in the Primary Tax Office Tebing Tinggi. The hypothesis proposed is: There is the influence of career development, work facilities, professional commitment, partial supervision and jointly on the performance of employees at the Primary Tax Office Tebing Tinggi. The study was conducted at the Tebing Tinggi Pratama Tax Service Office Jalan Sutoyo Number 32 Rambung Tebing Tinggi., With a population of 82 people, and a study sample of 82 people. Based on the results of the analysis, there is a significant influence between career development on the performance of the Pratama Tebing Tinggi Tax Office employee, because according to the results of the t count $>t$-table analysis (1.895>1.67) at $n=82$ with a significance level of 95\%. There is a significant influence between work facilities on the performance of the Primary Tax Office employees of Tebing Tinggi, the results of $t$ count analysis $>t$-table $(1,874>1.67)$ at $n=82$ with a level of significance of $95 \%$. There is a significant influence between professional commitment to the performance of the Primary Tax Service Office Tebing Tinggi, because according to the results of the analysis $t$ count $>t$-table (2.074> 1.67) at $n$ $=82$ with a significance level of 95\%. There is a significant influence between the supervision of the performance of the Pratama Tebing Tinggi Tax Office employee, because according to the results of the $t$-count analysis $>t$-table $(2.493>1.67)$ at $n=82$ with a significance level of $95 \%$. Together (multiple) there is a positive and significant influence on career development, work facilities, professional commitment and supervision of the performance of employees of the High Pratama Tax Service Office, because the F test results obtained F-count $>$ F table $(12,305>2,48)$. Thus the hypothesis proposed is accepted by the truth.
\end{abstract}

Keyword : Career development, work facilities, professional commitment and employee supervision and performance

ABSTRAK : Masalah dalam peneltian ini adalah bagaimana pengaruh pengembangan
karir, fasilitas kerja, komitmen profesi dan pengawasan kerja secara parsial maupun secara
bersamaan terhadap kinerja pegawai pada Kantor Pelayanan Pajak Pratama Tebing Tinggi
Tujuan penelitian :Untuk mengetahui pengaruh pengembangan karir, fasilitas kerja, komitmen
profesi dan pengawasan kerja secara parsial dan secara bersamaan terhadap kinerja pegawai
pada Kantor Pelayanan Pajak Pratama Tebing Tinggi. Hipotesis yang diajukan adalah :Ada
pengaruh pengembangan karir, fasilitaskerja, komitmen profesi,pengawasan secara parsial dan
secara bersama-sama terhadap kinerja pegawai pada Kantor Pelayanan Pajak Pratama Tebing
Tinggi.Penelitian dilakukan di Kantor Pelayanan Pajak Pratama Tebing Tinggi Jalan Sutoyo
Nomor 32 Tebing Tinggi., dengan populasi sebanyak82orang, dan sampel penelitian sebanyak 82
orang. Berdasarkan hasil analisis diperoleh Ada pengaruh yang signifikan antara pengembangan
karir terhadap kinerja pegawai pada Kantor Pelayanan Pajak Pratama Tebing Tinggi, karena
menurut hasil analisis thitung > t-tabel $(1,895>1,67)$ pada $n=82$ dengan taraf sifgifikansi
95\%.Ada pengaruh yang signifikan antara fasilitas kerja terhadap kinerja pegawai pada Kantor
Pelayanan Pajak Pratama Tebing Tinggi, hasil analisis thitung $>$ t-tabel $(1,874>1,67)$ pada $n=$ 
82 dengan taraf sifgnifikansi 95\%.Ada pengaruh yang signifikan antara komitmen profesi terhadap kinerja pegawai pada Kantor Pelayanan Pajak Pratama Tebing Tinggi, karena menurut hasil analisis thitung > t-tabel $(2,074>1,67)$ pada $n=82$ dengan taraf sifgnifikan 95\%. Ada pengaruh yang signifikan antara pengawasan kerja terhadap kinerja pegawai pada Kantor Pelayanan Pajak Pratama Tebing Tinggi, karena menurut hasil analisis thitung >t-tabel $(2,493>1,67)$ pada $n=82$ dengan taraf sifgifikan 95\%. Secara bersama-sama (multiple) terdapat pengaruh positif dan signifikan pengembangan karir, fasilitas kerja, komitmen profesi danpengawasan kerjaterhadap kinerja pegawai pada Kantor Pelayanan Pajak PratamaTebing Tinggi, karena hasil uji F didapat Nilai F-hitung > F tabel $(12,305>2,48)$. Dengan demikian hipotesis yang diajukan diterima kebenarannya.

Keyword: Pengembangan karir, fasilitas kerja, komitmen profesi dan pengawasan kerja serta kinerja pegawai.

\section{Pendahuluan}

Keberhasilan organisasi memang ditentukan oleh kinerja (job performance) dari karyawannya. Kinerja merupakan hasil kerja secara kualitas dan kuantitas yang telah dicapai oleh seseorang pegawai dalam melaksanakan tugasnya sesuai dengan tanggung jawab yang diberikan kepadanya (Mangkunegara, 2006:9). Setiap organisasi maupun perusahaan akan berusaha untuk meningkatkan kinerja pegawai untuk mencapai tujuan organisasi yang telah ditetapkan. Setaip organisasi senantiasa mengharapkan kinerja sumber daya manusianya baik, dengan demikian agar kinerja sumber daya manusia baik, maka organisasi perlu memperhatikan para personelnya.

Pimpinan bertanggung jawab mengusahakan pegawai agar mereka memiliki kemauan serta memiliki kesadaran maupun tanggung jawab yang tinggi, oleh sebab itu diperlukan usaha pimpinan untuk mengelola pegawai-pegawai dalam melakukan pekerjaan. Usaha-usaha pimpinan ini sesuai dengan fungsi manajemen dimana Manajemen adalah suatu proses yang khas yang terdiri dari tindakan planning, organizing, actuating serta controlling dimana pada masing-masing bidang digunakan baik ilmu pengetahuan maupun keahlian dan diikuti secara beruntun dalam rangka pencapaian sasaran yang telah ditetapkan semula. Pengembangan karir di Kantor Pelayanan Pajak Pratama Tebing Tinggi masih kurang, hal ini perlu diperbaiki agar kinerja pegawai semakin tinggi.

Salah satu dorongan seseorang bekerja pada suatu organisasi atau perusahaan adalah adanya kesempatan untuk maju yakni adanya kesempatan untuk meningkatkan karir karena hal ini merupakan suatu kebutuhan manusiai. Sudah menjadi sifat dasar dari manusia pada umumnya untuk menjadi lebih baik, lebih maju dari posisi yang dipunyai pada saat ini, karena itulah mereka menginginkan suatu kemajuan dalam hidupnya. Kemauan untuk maju di dalam organisasi sering disebut sebagai promosi dan promosi adalah salah satu upaya pengembangan sumber daya manusia. Dengan demikian seiring dengan adanya kemauan pegawai untuk maju atau meningkatkan karir maka tidak lepas dari peran pimpinan organisasi dalam upaya pengembangan pegawai. Karena pengembangan pegawai yang hanya tergantung dari usaha dari pegawai secara individual tidak sesuai dengan kepentingan organisasi. Oleh sebab itu perlu dukungan dari pimpinan baik pimpinan personalia maupun pimpinan organisasi sehubungan dengan aplikasi manajemen. Pimpinan sangat berperan penting dalam pengembangan pegawai, mulai dari program perencanaan, latihan dan pengembangan karir, dukungan manajemen, Akan tetapi juga tidak lepas dari pada kepemimpinan yang dilaksanakan dalam organisasi tersebut.

Selanjutnya fasilitas skerja di Kantor Pelayanan Pajak Pratama Tebing Tinggi belum lengkap dan masih kurang, hal ni juga akan berpengaruh terhadap rendahnya kinerja pegawai. Pegawai sebagai sumber daya manusia yang tidak terampil maupun yang terampil dan cakap memiliki kebutuhan yang sangat kompleks. Untuk memenuhi kebutuhan tersebut pegawai bekerja dan menerima upah atau gaji. Selain upah dan gaji mereka juga menuntut suatu kepuasan batin dalam bekerja, dimana kepuasaan ini diperoleh melalui fasilitas fasilitas seperti fasilitas kerja, kesehatan, perumahan. Apabila ini tidak terpenuhi akan menimbulkan suatu kontradiksi dari berbagai pihak, seperti pemerintah, organisasi buruh, terutama pegawai itu sendiri, bahkan kemungkinan organisasi internasional akan 
turut mencampurinya. Apabila ini terjadi dan tidak dapat diatasi maka akan mengakibatkan kerugian yang besar bagi organisasi yang berakhir pada berhentinya kegiatan dan operasional setiap organisasi. Dengan demikian tujuan organisasi yang telah ditetapkan tidak akan dapat tercapai. Untuk mendukung pelaksanaan tugas dalam mencapai tujuan organisasi perlu adanya fasilitas yang dibutuhkan oleh pegawai baik yang menyangkut fasilitas kerja maupun fasilitas sosial yang mendukung pelaksanaan tugas karyawan. Fasilitas-fasilitas yang disediakan organisasi tidak sama banyaknya, tergantung dari keadaan dan kondisi organisasi.

Selanjutnya di Kantor Pelayanan Pajak Pratama Tebing Tinggi komitmen profesi belum maksimal. Komitmen profesional pegawai terhadap organisasi sangat diperlukan untuk menciptakan iklim kerja yang profesional. Komitmen dapat diartikan sebagai sikap pegawai untuk tetap berada dalam organisasi dan terlibat dalam upaya-upaya mencapai misi, nilai-nilai dan tujuan organisasi. Komitmen individu terhadap organisasi ini dipandang penting karena pegawai yang memilki komitmen yang tinggi terhadap organisasi akan memiliki sikap yang profesional dan menjunjung tinggi nilai-nilai yang telah disepakati dalam organisasi. Untuk membangun komitmen individu terhadap organisasi dapat dilakukan melalui pendekatan lunak dan pendekatan keras.

Pengawasan yang dilakukan pimpinan terhadap pegawai juga masih rendah, dimana pengawasan pimpinan terhadap pekerjaan pegawai tidak maksimal akibatnya pegawai mengalami kendala dalam menyelesaikan tugasnya dan menyelesaikan tugasnya tanpa sesuai dengan yang diharapkan. Jelasnya pembagian kerja pegawai di Kantor Pelayanan Pajak Pratama Tebing Tinggi belum mencerminkan pembagian kerja yang sesuai dengan keahlian dan pendidikan pegawai, fasilitas kerja sebagai pendukung dan memperlancar pekerjaan pegawai masih kurang, sementara pengawasan yang dilakukan pimpinan juga kurang akhirnya prestasi kerja pegawai tidak maksimal sebagaiman yang diharapkan

Berdasarkan uraian tersebut di atas, merupakan alasan penulis yang melatar belakangi pembahasan penelitian dengan mengambil judul "Pengaruh pengembangan karir. Fasilitas kerja, komitmen profesi dan pengawasan kerja terhadap kinerja pegawai pada Kantor Pelayanan Pajak Pratama Tebing Tinggi:”.

Berdasarkan uraian diatas, adapun tujuan penelitian ini adalah :

a. Untuk mengetahui pengaruh pengembangan karir terhadap kinerja pegawai pada Kantor Pelayanan Pajak Pratama Tebing Tinggi

b. Untuk mengetahui pengaruh fasilitas kerja terhadap kinerja pegawai pada Kantor Pelayanan Pajak Pratama Tebing Tinggi.

c. Untuk mengetahui pengaruh komitmen profesi terhadap kinerja pegawai pada Kantor Pelayanan Pajak Pratama Tebing Tinggi.

d. Untuk mengetahui pengaruh pengawasan kerja terhadap kinerja pegawai pada Kantor Pelayanan Pajak Pratama Tebing Tinggi.

e. Untuk mengetahui pengaruh pengembangan karir, fasilitas kerja, komitmen profesi dan pengawasan kerja secara bersamaan terhadap kinerja pegawai pada Kantor Pelayanan Pajak Pratama Tebing Tinggi

\section{Metode Penelitian}

\subsection{Lokasi Penelitian}

Lokasi penelitian dilakukan di Kantor Pelayanan Pajak Pratama Tebing Tinggi Jalan Sutoyo Nomor 32 Tebing Tinggi.

\subsection{Populasi}

Populasi penelitian ini semua pegawai Kantor Pelayanan Pajak Pratama Tebing Tinggi selain kepala kantor yang berjumlah 83 orang.sebagaimana terlihat pada tabel berikut.

Tabel 1

Populasi Penelitian

\begin{tabular}{|c|l|c|}
\hline No & \multicolumn{1}{|c|}{ Jabatan } & Jumlah \\
\hline 1 & Kepala Kantor & 1 \\
\hline 2 & Kepala Seksi & 10 \\
\hline 3 & Supervisor & 3 \\
\hline 4. & Account Resentative & 27 \\
\hline 5. & Fungsional & 13 \\
\hline 6 & Pelaksana & 29 \\
\hline \multicolumn{2}{|c|}{ Jumlah } & 83 \\
\hline
\end{tabular}

Sumber : Data diolah, 2019

\section{Sampel}

Sampel penelitian ditetapkan berdasarkan ketentuan Arikunto (2012 : 120) menyebutkan bahwa : Apabila subjeknya kurang dari 100, lebih baik diambil semua sehingga penelitiannya merupakan populasi. Selanjutnya jika jumlah subjeknya besar dapat diambil 
antara $10-15 \%$, atau $20-25 \%$ atau lebih Berdasarkan tabel di atas maka sampel penelitian ditetapkan seluruh pegawai (tidak ikut kepala kantor) yakni 82 orang

\subsection{Defenisi Operasional}

Terdapat dua variabel dalam penelitian ini, variabel-variabel tersebut adalah Variabel Terikat, yaitu kinerja (Y), Variabel Bebas adalah Pengembangan Karir $\left(\mathrm{X}_{1}\right)$, Fasilitas $\left(\mathrm{X}_{2}\right)$, Komitmen Profesi $\left(\mathrm{X}_{3}\right)$, pengawasan kerja $\left(\mathrm{X}_{4}\right)$.

\subsection{Teknik Pengumpulan Data}

Teknik pengumpulan data dilakukan dengan pengumpulan data primer yaitu data yang dikumpulkan dari sumber-sumber asli untuk tujuan tertentu, atau data yang diperoleh dengan survei lapangan yang menggunakan metode pengumpulan data ordinal, yaitu : wawancara, Kuesioner.

\subsection{Teknik Analisa Data}

Teknik analisis data menggunakan validitas dan realibilitas, uji asumsi klasik dengan menggunakan uji Multikolinearitas, Multikolinearitas, Uji Heteroskedastisitas. Pengujian Hipotesis menggunakan uji regresi berganda.

\section{HASIL DAN PEMBAHASAN}

\subsection{Analisis Regresi}

Analisis regresi digunakan untuk menganalisis data hasil penelitian dengan maksud untuk memperoleh gambaran hubungan fungsional antara variabel bebas dengan variabel terikat Hubungan fungsional antara variabel bebas dengan variabel terikat digunakan analisis regresi linier berganda

Berdasarkan analisis regresi linier ganda (Multiple) sebagaimana pada tabel 2 diperoleh koefisien regresi sebagai berikut.

Tabel 2

Koefisien Regresi

\begin{tabular}{|c|c|c|c|c|c|c|}
\hline \multirow{2}{*}{\multicolumn{2}{|c|}{ Model }} & \multicolumn{2}{|c|}{$\begin{array}{l}\text { Unstandardized } \\
\text { Coefficients }\end{array}$} & \multirow{2}{*}{$\begin{array}{l}\text { Standardized } \\
\text { Coefficients } \\
\text { Beta }\end{array}$} & \multirow[b]{2}{*}{$\mathrm{T}$} & \multirow[b]{2}{*}{ Sig. } \\
\hline & & $\mathrm{B}$ & Std. Error & & & \\
\hline \multirow[t]{5}{*}{1} & (Constant) & 24,141 & 1,912 & & 12,627 &, 000 \\
\hline & Pengembangan karir & , 109 & ,058 & 231 & 1,895 & ,062 \\
\hline & Fasilitas kerja & , 128 & ,068 & 220 & 1,874 & ,065 \\
\hline & Komitmen profesi & ,019 & 251 & ,037 & 2,074 & 941 \\
\hline & Pengawasan &, 128 & 260 & 246 & 2,493 & 624 \\
\hline
\end{tabular}

Sumber : Hasil SPSS, 2019

Berdasarkan table 2 diperoleh koefisien regresi variabel Pengembangan karir0,109Fasilitas kerja $=0,128$, Komitmen profesi0,019, Pengawasan kerja 0,128 dan konstanta 24,141, maka dapat dituliskan persamaan regresi sebagai berikut.

$$
Y=24,141+0,109 X_{1}+0,128 X_{2}+0,019 X_{3}+
$$

Persamaan di atas menunjukkan konstanta bernilai positip dan nilai koefisien regresi Pengembangan karir, Fasilitas kerja,Komitmen profes dan pengawasan kerja positip, Hal ini memberi gambaran bahwa perubahan rata-rata variabel Kinerja Pegawai (Y) tergantung dari perubahan variabel Pengembangan $\operatorname{karir}\left(\mathrm{X}_{1}\right)$, Fasilitas kerja $\left(\mathrm{X}_{2}\right)$ Komitmen profesi $\left(\mathrm{X}_{3}\right)$ dan Pengawasan kerja. Artinya apabila Pengembangan karir, Fasilitas kerja, Komitmen profesidan pengawasan kerjaditingkatkan (semakin baik) akan diikuti perubahankinerja pegawai. Perubahan ini merupakan peningkatan apabila bertanda positip dan penurunan atau pengurangan jika bertanda negatif.Hal ini menunjukkan bahwa ada pengaruh Pengembangan karirFasilitas kerja, Komitmen profesi dan Pengawasan kerjaterhadap kinerja pegawai.

\subsection{Uji Hipotesis}

\subsubsection{Uji t- (Parsial)}

Untuk mengetahui pengaruh variabel bebas terhadap variabel terikat secara parsial digunakan uji t, dimana dengan ketentuan :

$\mathrm{t}-$ hitung $\leq \mathrm{t}-$ tabel ...............tidak ada pengaruh variabel bebas terhadap variabel terikat secara parsial

t- hitung > t- tabel ................Ada pengaruh variabl bebas terhadap variabel terikat secara parsial

derajat kebebasan $(\mathrm{dk})=\mathrm{n}-2$ dan Tingkat

kepercayaan $\alpha=0,05$, 
Tabel 3

Uji T (Parsial)

Coefficients $^{\mathrm{a}}$

\begin{tabular}{|c|c|c|c|c|c|}
\hline \multirow[b]{2}{*}{ Model } & \multicolumn{2}{|c|}{$\begin{array}{l}\text { Unstandardized } \\
\text { Coefficients }\end{array}$} & \multirow{2}{*}{$\begin{array}{l}\text { Standardized } \\
\text { Coefficients } \\
\text { Beta }\end{array}$} & \multirow[b]{2}{*}{$\mathrm{t}$} & \multirow[b]{2}{*}{ Sig. } \\
\hline & $\mathrm{B}$ & Std. Error & & & \\
\hline $1 \quad$ (Constant) & 24.141 & 1.912 & & 12.627 & .000 \\
\hline Pengembangan karir & .109 & .058 & .231 & 1.895 & .062 \\
\hline Fasilitas kerja & .128 & .068 & .220 & 1.874 & .065 \\
\hline Komitmen profesi & .019 & .251 & .037 & 2.074 & .941 \\
\hline Pengawasan & .128 & .260 & 246 & 2.493 & .624 \\
\hline
\end{tabular}

Berdasarkan hasil analisis pada tabel 3 diatas; diperoleh nilai tPengembangan karir= 1,895 , sedangkan t-tabel dengan $\mathrm{dk} 82$ (Lampiran) sebesar 1,67maka thitung > t-tabel dengan demikian secara parsial ada pengaruh yang signifikan antara Pengembangan karirterhadap kinerjapegawai.

Selanjutnya nilai $\mathrm{t}$ Fasilitas kerja $=1,874$, sedangkan t-tabel dengan $\mathrm{dk} 82$ (Lampiran) sebesar 1,67 maka $t$ hitung $>\mathrm{t}$ tabel dengan demikian secara parsial ada pengaruh yang signifikan antara Fasilitas kerja terhadap Kinerja Pegawai..

Nilai t Komitmen profesi $=2,074$, sedangkan t-tabel dengan dk 82 (Lampiran) sebesar 1,67 maka $t$ hitung $>t$ tabel dengan demikian secara parsial ada pengaruh yang signifikan antara Komitmen profesiterhadap Kinerja Pegawai. Nilai t Pengawasan kerja $=2,493$, sedangkan ttabel dengan dk 82 (Lampiran) sebesar 1,67 maka $\mathrm{t}$ hitung $<\mathrm{t}$ tabel dengan demikian secara parsial ada pengaruh positifyang signifikan antara Pegawai

PengawasankerjaterhadapKinerja

\subsubsection{Uji F (Mulktipel)}

Untuk mengetahui pengaruh variabel bebas secara bersama-sama terhadap variabel terikat digunakan uji-F, (Sudjana, 2013:355) dengan rumus:

$$
: F_{h i t}=\frac{J K_{r e g} / k}{J K_{r e s} /(n-k-1)}
$$

Dimana :

$\mathrm{JK}_{\mathrm{reg}}=$ Jumlah kuadrat regresi

$\mathrm{JK}_{\text {reg }}=$ Jumlah kuadrat residu

$\mathrm{n}=$ Jumlah Sampel

$\mathrm{K}=$ Jumlah varians

Jika : $\mathrm{F}$ hitung $>\mathrm{F}$ tabel : Hipotesis Alternatip (Ha) diterima

$\mathrm{F}$ hitung $<\mathrm{F}$ tabel : Hipotesis (Ho)

ditolak

Penelitian ini menggunakan tingkat

kepercayaan $95 \%(\alpha=0.05)$

Tabel 4

Uji F(Simultan)

ANOVA $^{\mathrm{a}}$

\begin{tabular}{|ll|r|r|r|r|c|}
\hline \multicolumn{2}{|l|}{ Model } & \multicolumn{1}{|c|}{$\begin{array}{c}\text { Sum of } \\
\text { Squares }\end{array}$} & df & Mean Square & F & Sig. \\
\hline 1 & Regression & 50.509 & 4 & 12.627 & 12.305 & $.000^{\mathrm{b}}$ \\
& Residual & 79.016 & 77 & 1.026 & & \\
& Total & 129.524 & 81 & & & \\
\hline
\end{tabular}

a. Dependent Variable: Kinerja Pegawai

b. Predictors: (Constant), Pengawasan, Fasilitas kerja, Pengembangan karir, Komitmen profesi

Berdasarkan analisis varians (Anova) pada tabel 4 diketahui nilai F-hitung sebesar 12,305sedangkan nilai F-tabel (Lampiran) dengan $\mathrm{dk}$ pembilang $4 \mathrm{dan} \mathrm{dk}$ penyebut 77 adalah sebesar 2,48 dimana F-hitung $>\mathrm{F}$ tabel $(12,305>2,48)$ maka dapat disebutkan bahwa secara bersama-sama (multiple) terdapat pengaruh yang signifikan Pengembangan karir, Fasilitas kerja, Komitmen profesi dan pengawasan kerjaterhadap kinerja pegawai. Dengan demikian hipotesis yang diajukan diterima kebenarannya. 


\subsection{Uji Determinasi}

Berdasarkan hasil analisis data Pengembangan karirdiKantor Pelayanan Pajak Pratama Tebing Tinggikategori kurang baik, Fasilitas kerja kurang lengkap, Komitmen profesikurang baik, pengawasan kerja kurang baik, dan Kinerja Pegawai kurang tinggi.Hasil analisis data sesuai hasil ANOVA Kinerja Pegawai dapat meningkat apabilaPengembangan karirFasilitas kerjaKomitmen profesi, pengawasan kerjaditingkatkan. Oleh sebab itu juga pengujian hipotesis diperoleh terdapat pengaruh signifikan Pengembangan karir, Fasilitas kerj, Komitmen profesi dan Pengawasan kerjaterhadap kinerja pegawai. Apabila Pengembangan karir,Fasilitas kerja ,Komitmen profesi dan pengawasan kerjaditingkatkan $1 \%$ maka Kinerja Pegawai akan naik 1\%.Besarnya pengaruh Pengembangan karir, Fasilitas kerja, Komitmen profesidan Pengawasan kerjaterhadap Kinerja Pegawai dapat diketahui melalui uji determinasi (D) dimana $D=R^{2} x$ $100 \%$. Hasil analisis pada model summary sebagaimana pada tabel 5 sebagai berikut.

Tabel 5

Model Summary

\begin{tabular}{|l|r|r|r|r|rr|}
\hline Model & \multicolumn{1}{|l|}{ R } & R Square & $\begin{array}{l}\text { Adjusted R } \\
\text { Square }\end{array}$ & $\begin{array}{l}\text { Std. Error of } \\
\text { the Estimate }\end{array}$ & Durbin-Watson \\
\hline 1 &, $624^{\mathrm{a}}$ &, 390 &, 358 & 1,01300 & & 1,563 \\
\hline
\end{tabular}

a. Predictors: (Constant), Pengawasan, Fasilitas kerja, Pengembangan karir, Komitmen profesi

b. Dependent Variable: Kinerja Pegawai

Berdasarkan tabel 5 diketahui $\mathrm{R}^{2}=0,390$ maka $\mathrm{D}=0,390 \mathrm{x} 100 \%$ sehingga $\mathrm{D}=39 \%$. Dengan demikian pengaruh Pengembangan karir, Fasilitas kerja,komitmen profesi dan Pengawasan kerjaterhadap Kinerja Pegawai secara bersama-sama sebesar $39 \%$ yang berarti $61 \%$ lagi yang mempengaruhi kinerja pegawai ditentukan faktor lain yang tidak diteliti dalam penelitian ini.

\section{Kesimpulan}

Sesuai hasil analisis penelitian maka dapat diamil kesimpulan sesuai tujuan penelitian yang dikemukakan.

a. Ada pengaruh yang signifikan antara pengembangan karir terhadap kinerja pegawai pada Kantor Pelayanan Pajak Pratama Tebing Tinggi, karena menurut hasil analisis thitung > t-tabel $(1,895>1,67)$ pada $\mathrm{n}=82$ dengan taraf sifgifikansi $95 \%$.

b. Ada pengaruh yang signifikan antara fasilitas kerja terhadap kinerja pegawai pada Kantor Pelayanan Pajak Pratama Tebing Tinggi, hasil analisis thitung $>$ t-tabel $(1,874>1,67)$ pada $\mathrm{n}=82$ dengan taraf sifgnifikansi $95 \%$.

c. Ada pengaruh yang signifikan antara komitmen profesi terhadap kinerja pegawai pada Kantor Pelayanan Pajak Pratama Tebing Tinggi, karena menurut hasil analisis thitung > t-tabel $(2,074>1,67)$ pada $\mathrm{n}=82$ dengan taraf sifgnifikan $95 \%$ d. Ada pengaruh yang signifikan antara pengawasan terhadap kinerja pegawai pada Kantor Pelayanan Pajak Pratama Tebing Tinggi, karena menurut hasil analisis thitung $>$ t-tabel $(2,493>1,67)$ pada $\mathrm{n}=82$ dengan taraf sifgifikan $95 \%$.

e. Secara bersama-sama (multiple) terdapat pengaruh positif dan signifikan pengembangan karir, fasilitas kerja, komitmen profesi danpengawasan terhadap kinerja pegawai pada Kantor Pelayanan Pajak Pratama Tebing Tinggi, karena hasil uji $\mathrm{F}$ didapat Nilai F-hitung $>\mathrm{F}$ tabel $(12,305>2,48)$. Dengan demikian hipotesis yang diajukan diterima kebenarannya.

\section{DAFTAR PUSTAKA}

Alwi, Syafaruddin, 2011. Manajemen Sumber Daya Manusia, BPFE, UGM Yogyakarta.

Amin Wijaya Tunggal, 2012, Manajemen Suatu Pengantar, Cetakan Pertama, Jakarta : Rineka Cipta Jaya

Arikunto, Suharsimi, 2012. Prosedur Penelitian Suatu Pendekatan Praktek, Rineka Cipta, Jakarta.

Daliman, A, 2012, Perluasan Pendidikan Non Formal sebagai Kebijaksanaan Dalam Pembinaan Pegawai, Cakrawala, Jakarta.

Dwiyanto, Agus, 2013, Penilaian Kinerja organisasi Pelayanan Publik, Yogyakarta : UGM

Gie, The Liang, 2013, Administrasi Perkantoran Modern, Yogyakarta : Liberty 
Gouzali Saydam, 2012, Kamus Istilah Kepegawaian, Jakarta : Bina Aksara.

Handoko, T. Hani, 2012, Manajemen Personalia dan Sumber Daya Manusia, Cetakan Pertama, Jakarta : Liberti.

Irawan, 2013. Pengantar Ekonomi Perusahaan, Yogyakarta : UGM.

Kreitner Robert, dan Angelo Kinicki, 2013, Perilaku Organisasi, Terjemahan Erly Suandy, Penerbit Salemba Empa, Jakarta

Koesmono, Teman H. 2015, Pengaruh Budaya Organisasi, Terhadap Motivasi dan Kepuasan Kerja Serta Kinerja Karyawan Pada Sub Sektor Industri Pengolahan Kayu Skala Menengah Di Jawa Timur, Jurnal Manajemen \& Kewirausahaan, Vol. 7 No. 2]

Mangkunegara, A. 2010, Evaluasi Kinerja SDM, Bandung : Refika Aditama

Mar,at, 2012, Pimpinan dan Kepemimpinan, Jakarta : Ghalia Indonesia

Mitrani, Alain, 2009, Manajemen Sumber Daya Manusia Berdasarkan Kompetensi, Jakarta : Pustaka Utama Grafiti

Moenir, A.S, 2010, Pendekatan Manusiawi dan Organisasi Terhadap Pembinaan Pegawai, Gunung Agung, Jakarta.

Moekijat, 2012. Manajemen Sumber daya Manusia. Jakarta : Rineka Cipta

Nawawi, Hadari, 2013, Metode Penelitian Bidang Sosial, Gajah Mada University Press, Yogyakarta

Pramono,Cahyo (2012). Pengawasan. Waspada Online (www.waspada.co.id)

Siagian, S.P,2011 : Organisasi, Kepemimpinan dan Prilaku Organisasi, Gunung Agung, Jakarta.
Sedarmayanti, 2012, Sumberdaya Manusia dan Produktivitas Kerja. Bandung:

Ilham Jaya

Sinungan, Muchdarsyah, 2011, Produktivitas Apa dan Bagaimana, Jakarta: Bumi Aksara

Soeprihanto, John, 2011, Manajemen Personalia, BPFE, Gajah Mada, Yogyakarta

Soesmanto, Bintang 2009. Pengawasan Intern Pada Menko Kesra. (www.menkokesra.com)

Sudarmono, Indriyono Gito, 2010, Sistem Perencanaan dan Pengawasan Manajemen, Revisi, Salemba Empat, Jakarta.

Sugiyono, 2010, Metode Penelitian Administrasi, Alfabeta, Bandung.

Tangkilisan, Hessel Nogi, S, 2015, Manajemen Publik, Jakarta : PT. Grasindo

Waldiman, David A., 2010, The Contribution of Total Quality Management to a Theory of Work performance, Academy of Management Review, Vol 19 No.3,

Wahjosumidjo, 2010 : Kepemimpinan dan Motivasi, Ghalia Indonesia, Jakarta.

Widodo, Joko, 2011, Telaah Dimensi Akuntabilitas dan Kontrol Birokrasi Pada Era Desentralisasi dan otonomi Daerah, Surabaya: Insan Cendekia

Wijaya Tony, Cepar Menguasai SPSS Untuk Olah \& Interpretasi Data Penelitian, 2011, Cahaya Atma Yogyakarta. 